\title{
Steroid 21-hydroxylase gene variants and late-life depression
}

\author{
Marie-Laure Ancelin ${ }^{1 *} \mathbb{D}$, Joanna Norton ${ }^{1}$, Karen Ritchie ${ }^{1,2}$, Isabelle Chaudieu ${ }^{1}$ and Joanne Ryan ${ }^{3}$
}

\begin{abstract}
Objectives: A feature of late-life depression is alterations of the stress hormone system. The CYP21A2 gene encodes for the steroid 21-hydroxylase enzyme which is required for the biosynthesis of mineralocorticoids and glucocorticoids, two main components of the stress response in humans. Variants in the CYP21A2 gene could influence risk of late-life depression, but this has not been examined. This study investigated possible associations between five variants in the CYP21A2 gene and late-life depression in 1007 older community-dwelling men and women.

Results: In multivariate logistic regression model, significant associations were found between three single-nucleotide polymorphisms (rs389883, rs437179, and rs630379) and depression in women specifically (OR ranging from 1.51 to 1.68, p-values 0.025 to 0.0045 ), and the two latter remained significant after correction for multiple testing. Variants of the CYP21A2 gene appear as susceptibility factors for late-life depression in a sex-specific manner, independently of somatic and neuropsychiatric comorbidity.
\end{abstract}

Keywords: Late-life depression, Older adults, Population-based study, Stress, Corticosteroids, Single-nucleotide polymorphisms

\section{Introduction}

A feature of late-life depression (LLD) is alterations of the stress hormone system [1]. Stress hormone secretion can be influenced by a number of factors such as age, sex, comorbidity, and genetic sensitivity to environmental stress [1, 2]. Recent evidence suggests that depression can be divided into a reactive subtype more vulnerable to intrinsically stress-related environmental factors and neurodevelopmental mechanisms and an endogenous subtype with a strong biological and/or genetic basis and no apparent environmental precipitants [3, 4]. Endogenous depression may involve genes related to serotonergic system and hypothalamic-pituitary-adrenal (HPA) axis $[3,5-7]$.

The CYP21A2 (cytochrome P450, family 21, subfamily A, polypeptide 2) gene encodes for the steroid

*Correspondence: marie-laure.ancelin@inserm.fr

${ }^{1}$ INM, Univ Montpellier, INSERM, Montpellier, France

Full list of author information is available at the end of the article 21-hydroxylase enzyme which catalyzes the conversion of progesterone to 11-deoxycorticosterone and 17-hydroxyprogesterone to 11-deoxycortisol in the biosynthesis of mineralocorticoids (aldosterone) and glucocorticoids (cortisol), the two main components of stress response in humans [8]. Mild to severe 21-hydroxylase deficiency notably causes changes to sex and adrenal hormone activities and leads to steroid hormone imbalances [9]. It can lead to a shunt away from cortisol and aldosterone synthesis to form androstenedione, which can drive the synthesis of androgens or lead to estrone via aromatase [10].

Altered cortisol and sex steroid levels and psychiatric disorders have been reported in clinical studies of young adults with 21-hydroxylase deficiency [11, 12], especially in women [13]. In older general population, Velders et al. found weak associations between some CYP21A2 polymorphisms and cortisol secretion [14]. For three variants, an association with a broad depression phenotype (depressive symptoms combined with major depressive 
disorder diagnosis) was reported from a meta-analysis of genome-wide association studies [15]. None of these studies examined women specifically, although female hormones can influence both depression [16] and the HPA axis response to stress [17], especially in older adults [2]. There is also clear evidence for female specificity in the genetic basis of both depression as well as cortisol secretion and response to stress $[18,19]$. However, despite the fact that stress hormones play a clear role in depression, the possible influence of genes involved in corticosteroid biosynthesis on depression is still poorly explored [20].

In this study, we investigated the relationships between CYP21A2 genetic variants and depression in a large cohort of older adults while taking into account multiple causes of depression, including vascular factors and neuropsychiatric comorbidity. We hypothesized that genetic variation within $C Y P 21 A 2$ would contribute to the risk of LLD, independently of comorbidity, and that these relationships could be modified by sex.

\section{Main text \\ Methods \\ Design and setting of the study}

Community-dwellers aged 65 years or older were selected by random sampling from electoral roles in the Montpellier district, France [21]. Ethics approval was given by the national ethics committee (Ethical Committee of Sud Méditerranée III and University Hospital of Kremlin-Bicêtre, France) and all participants provided informed consent. Participants underwent standardized clinical assessments as well as health (socio-demographic and anthropometric characteristics, lifestyle, medical history) and psychiatric interviews.

\section{Genotyping}

This study was based on a sample of 1007 non-demented participants who underwent depression assessment and agreed to provide buccal samples for DNA. Five polymorphisms (rs389883, rs437179, rs429608, rs438999, and rs630379) were selected based on their potential association with cortisol secretion [14] and a recent metaanalysis of depression genome-wide association studies [15]. Genotyping was performed by LGC Genomics, UK, using the KASP SNP genotyping system [22].

\section{Clinical variables}

Lifetime depression and anxiety disorders were diagnosed according to DSM-IV criteria [21] using the Mini-International Neuropsychiatric Interview (MINI), a standardized psychiatric examination validated in the general population [23]. The Center for Epidemiologic Studies-Depression Scale (CES-D), validated in older general population, was used to evaluate current depressive symptomatology [24]. In older adults, LLD covers a range of mild to severe depressive symptoms which does not always correspond to the DSM criteria for major depressive disorder, despite devastating consequences $[25,26]$. To adequately capture this construct, case-level LLD was defined as a MINI diagnosis of current major depressive disorder or clinical level of depressive symptomatology (CES-D score $\geq 16$ ) [22]. Cognitive impairment was defined as having a Mini-Mental State Examination (MMSE) score <26 [27]. MMSE and MINI were administered by psychologists and psychiatric nurses and positive cases of depression were reviewed by a panel of psychiatrists. Dementia was diagnosed by a neurologist as part of a standardized examination and validated by a panel of independent neurologists [28].

\section{Statistical analysis}

Associations between CYP21A2 polymorphisms and LLD were assessed using logistic regression adjusted for age and after stratification by sex. Multivariate analyses further adjusted for cognitive impairment, body mass index, cardiovascular pathologies, past major depressive disorder, and current anxiety disorder. SAS (v9.4, SAS Institute, NC, USA) was used for the statistical analyses with a significance level of $p<0.05$. Given that five SNPs were investigated, the Bonferroni corrected $\mathrm{p}$-value was 0.01 .

\section{Results}

One quarter of the 1007 participants were identified as having LLD (Table 1). They were more frequently women, with a lower education level and more likely to have cognitive impairment, past major depressive disorder, current anxiety disorder and to use antidepressant than non-depressed participants $(\mathrm{p} \leq 0.004)$. The CYP21A2 genotype frequencies were not significantly different from those predicted by Hardy-Weinberg equilibrium ( $p>0.21$ for all SNPs) (Additional file 1 Table S1). Owing to the small number of homozygotes for the minor allele of all polymorphisms $(<4 \%)$, these homozygotes were combined with the heterozygotes for analysis.

In age-adjusted regression model, rs389883, rs437179, and $r s 630379$ were associated with an increased risk of LLD in the whole sample and in women specifically (Table 2). Women with minor alleles of $r s 389883$, rs437179, and rs630379 had a 51-68\% increased risk of depression compared with homozygotes for the major allele, and the two latter remained significant after Bonferroni correction. The same pattern was observed in the multivariate-adjusted regression models or when changing the depression outcome to also include participants 
Table 1 Baseline characteristics of participants according to prevalent late-life depression (LLD) ${ }^{\mathrm{a}}\left(\mathrm{N}=1007^{\mathrm{b}}\right)$

\begin{tabular}{|c|c|c|c|c|}
\hline Characteristic & $\begin{array}{l}\text { No LLD }(n=751 \text {, } \\
74.58 \%)\end{array}$ & $\operatorname{LLD}(n=256,25.42 \%)$ & $\begin{array}{l}\text { LLD vs no LLD (OR } \\
\left.[95 \% \mathrm{CI}]^{\mathrm{C}}\right)\end{array}$ & Wald test P-value \\
\hline Age (years) mean (sd) & $71.41(4.39)$ & $71.97(4.46)$ & $1.03[0.99 ; 1.06]$ & 0.08 \\
\hline Sex (female) & $414(55.13)$ & $188(73.44)$ & $2.24[1.64 ; 3.07]$ & $<0.0001$ \\
\hline Education ( $\geq 12$ years schooling) & $231(30.76)$ & $44(17.19)$ & $0.54[0.37 ; 0.78]$ & 0.001 \\
\hline \multicolumn{5}{|l|}{ Body mass index $\left(\mathrm{kg} / \mathrm{m}^{2}\right)$} \\
\hline Normal $(<25)$ & $427(56.86)$ & $142(55.47)$ & 1 & \\
\hline Overweight (25-29) & $275(36.62)$ & $89(34.77)$ & $1.18[0.86 ; 1.63]$ & 0.30 \\
\hline Obese $(\geq 30)$ & $49(6.52)$ & $25(9.77)$ & $1.61[0.95 ; 2.72]$ & 0.08 \\
\hline Diabetes (fasting glycemia $>7 \mathrm{mmol} \mathrm{I}^{-1}$ or treated) & $51(6.84)$ & $15(5.86)$ & $1.11[0.60 ; 2.04]$ & 0.75 \\
\hline Cardiovascular ischemic pathologies $^{d}$ & $78(10.39)$ & $27(10.55)$ & $1.17[0.73 ; 1.89]$ & 0.51 \\
\hline Hypertension (>95/160 mmHg or treated) & $335(44.61)$ & $112(43.75)$ & $0.97[0.72 ; 1.30]$ & 0.82 \\
\hline Cognitive impairment (MMSE score <26) & $62(8.26)$ & $40(15.63)$ & $1.88[1.22 ; 2.89]$ & 0.004 \\
\hline History of major depression & $153(20.37)$ & $95(37.11)$ & $2.05[1.49 ; 2.81]$ & $<0.0001$ \\
\hline Antidepressant use & $15(2.00)$ & $28(10.94)$ & $5.09[2.65 ; 9.78]$ & $<0.0001$ \\
\hline Current anxiety disorder & $70(9.32)$ & $63(24.61)$ & $2.86[1.95 ; 4.20]$ & $<0.0001$ \\
\hline
\end{tabular}

${ }^{a}$ Corresponds to current major depression or a CES-D score $\geq 16$

${ }^{\mathrm{b}}$ Except for diabetes $(\mathrm{N}=1002)$

${ }^{\mathrm{C}}$ Adjusted for age (continuous), except for age (unadjusted)

${ }^{\mathrm{d}}$ A history of angina pectoris, myocardial infarction, stroke, cardiovascular surgery and arteritis

Table 2 Logistic regression analysis for the association between CYP21A2 polymorphisms and prevalent late-life depression (LLD) in the whole sample and according to sex

\begin{tabular}{|c|c|c|c|c|c|c|c|c|c|c|c|c|}
\hline \multirow[t]{3}{*}{ SNP and genotype } & \multicolumn{4}{|c|}{ Whole sample $(\mathrm{N}=1007)$} & \multicolumn{4}{|c|}{ Men $(N=405)$} & \multicolumn{4}{|c|}{ Women $(\mathrm{N}=602)$} \\
\hline & No LLD & LLD & OR $[95 \% \mathrm{Cl}]^{b}$ & $p$ & No LLD & LLD & OR $[95 \% \mathrm{CI}]^{\mathrm{b}}$ & $p$ & No LLD & LLD & OR $[95 \% \mathrm{Cl}]^{b}$ & $\mathrm{p}$ \\
\hline & $\%$ & $\%$ & & & $\%$ & $\%$ & & & $\%$ & $\%$ & & \\
\hline$r s 389883, n$ & 733 & 252 & & & 327 & 68 & & & 406 & 184 & & \\
\hline AA & 64.26 & 58.73 & - & - & 61.47 & 63.24 & - & - & 66.50 & 57.07 & & \\
\hline$A C+C C$ & 35.74 & 41.27 & $1.32[0.98 ; 1.77]$ & 0.07 & 38.53 & 36.76 & $0.98[0.57 ; 1.69]$ & 0.94 & 33.50 & 42.93 & $1.51[1.05 ; 2.16]$ & 0.025 \\
\hline rs437179, n & 739 & 251 & & & 331 & 65 & & & 408 & 186 & & \\
\hline GG & 64.28 & 58.57 & - & - & 60.42 & 64.62 & - & - & 67.40 & 56.45 & & \\
\hline $\mathrm{GT}+\mathrm{TT}$ & 35.72 & 41.43 & $1.34[0.99 ; 1.80]$ & 0.056 & 39.58 & 35.38 & $0.87[0.50 ; 1.52]$ & 0.63 & 32.60 & 43.55 & $1.61[1.13 ; 2.30]$ & 0.009 \\
\hline$r s 429608, n$ & 722 & 251 & & & 326 & 65 & & & 396 & 186 & & \\
\hline GG & 67.73 & 69.32 & - & - & 66.87 & 73.85 & - & - & 68.43 & 67.74 & & \\
\hline$A G+A A$ & 32.27 & 30.68 & $0.93[0.68 ; 1.27]$ & 0.64 & 33.13 & 26.15 & $0.70[0.38 ; 1.28]$ & 0.25 & 31.57 & 32.26 & $1.03[0.71 ; 1.50]$ & 0.86 \\
\hline rs438999, n & 746 & 255 & & & 335 & 68 & & & 411 & 187 & & \\
\hline $\mathrm{TT}$ & 77.08 & 78.43 & - & - & 77.61 & 79.41 & - & - & 76.64 & 78.07 & & \\
\hline$C T+C C$ & 22.92 & 21.57 & $0.92[0.65 ; 1.30]$ & 0.64 & 22.39 & 20.59 & $0.87[0.45 ; 1.65]$ & 0.66 & 23.36 & 21.93 & $0.93[0.61 ; 1.41]$ & 0.73 \\
\hline rs630379, n & 746 & 254 & & & 336 & 67 & & & 410 & 187 & & \\
\hline GG & 65.28 & 59.06 & - & - & 61.90 & 67.16 & - & - & 68.05 & 56.15 & & \\
\hline $\mathrm{GT}+\mathrm{TT}$ & 34.72 & 40.94 & $1.35[1.00 ; 1.82]$ & 0.047 & 38.10 & 32.84 & $0.82[0.47 ; 1.44]$ & 0.49 & 31.95 & 43.85 & $1.68[1.17 ; 2.40]$ & 0.0045 \\
\hline
\end{tabular}

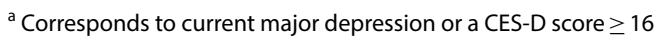

${ }^{\mathrm{b}}$ Model adjusted for age (and sex for whole sample)

not reaching our criteria for LLD but currently using antidepressants (Table 3).
Discussion

Three of five SNPs examined, rs389883, rs437179, and $r s 630379$, were associated with a more than $50 \%$ 
Table 3 Multivariate logistic regression analysis ${ }^{a}$ for the association between CYP21A2 polymorphisms and prevalent late-life depression (LLD) in women ( $N=602)$

\begin{tabular}{|c|c|c|c|c|c|c|c|c|}
\hline SNP and genotype & $\begin{array}{l}\text { No } \text { LLD }^{\mathbf{b}} \\
\%\end{array}$ & $\begin{array}{l}\text { LLD }^{\mathbf{b}} \\
\%\end{array}$ & OR $[95 \% \mathrm{CI}]^{\mathrm{b}}$ & $p^{b}$ & $\begin{array}{l}\text { No LLD' } \\
\%\end{array}$ & $\begin{array}{l}\text { LLD }^{c} \\
\%\end{array}$ & OR $[95 \% \mathrm{CI}]^{\mathrm{c}}$ & $p^{c}$ \\
\hline$r s 389883, n$ & 406 & 184 & & & 394 & 196 & & \\
\hline $\mathrm{AA}$ & 66.50 & 57.07 & - & - & 67.26 & 56.12 & & \\
\hline$A C+C C$ & 33.50 & 42.93 & $1.47[1.01 ; 2.13]$ & 0.04 & 32.74 & 43.88 & $1.58[1.10 ; 2.29]$ & 0.014 \\
\hline$r s 437179, n$ & 408 & 186 & & & 396 & 198 & & \\
\hline GG & 67.40 & 56.45 & - & - & 67.93 & 56.06 & & \\
\hline $\mathrm{GT}+\mathrm{TT}$ & 32.60 & 43.55 & $1.59[1.10 ; 2.30]$ & 0.01 & 32.07 & 43.94 & $1.65[1.14 ; 2.38]$ & 0.0075 \\
\hline$r s 429608, n$ & 396 & 186 & & & 384 & 198 & & \\
\hline GG & 68.43 & 67.74 & - & - & 68.23 & 68.18 & & \\
\hline$A G+A A$ & 31.57 & 32.26 & $0.96[0.65 ; 1.42]$ & 0.85 & 31.77 & 31.82 & $0.95[0.64 ; 1.39]$ & 0.78 \\
\hline$r s 438999, n$ & 411 & 187 & & & 399 & 199 & & \\
\hline TT & 76.64 & 78.07 & - & - & 76.69 & 77.89 & & \\
\hline $\mathrm{CT}+\mathrm{CC}$ & 23.36 & 21.93 & $0.81[0.53 ; 1.26]$ & 0.36 & 23.31 & 22.11 & $0.84[0.54 ; 1.29]$ & 0.42 \\
\hline rs630379, n & 410 & 187 & & & 398 & 199 & & \\
\hline GG & 68.05 & 56.15 & - & - & 68.84 & 55.28 & & \\
\hline $\mathrm{GT}+\mathrm{TT}$ & 31.95 & 43.85 & $1.65[1.14 ; 2.39]$ & 0.008 & 31.16 & 44.72 & $1.77[1.23 ; 2.56]$ & 0.002 \\
\hline
\end{tabular}

${ }^{a}$ Model adjusted for age, ischemic pathologies, cognitive impairment (MMSE $\left.<26\right)$, body mass index, past major depression, and current anxiety disorder

${ }^{b}$ Corresponds to current major depression or a CES-D score $\geq 16$

${ }^{c}$ Corresponds to current major depression or a CES-D score $\geq 16$ or currently using antidepressant or treated with antidepressants (combined prevalence $33.4 \%$ )

increased risk of LLD in women specifically, independently of potential physical and mental health-related confounders. Our finding of female-specific associations aligns with what has been reported in the literature, with both age and sex modifying the cortisol response to challenge. A meta-analysis reported a consistent effect of age upon cortisol responses which was almost three-fold stronger in older women than men [2]. Female-specific genetic determinants of morning cortisol levels have also been reported in a genomewide study [19]. Sex hormones can influence the HPAaxis response to stress, and a more potent reaction to stress has been observed in females [17] and they can also influence depression. In clinical studies, specific alterations in cortisol and sex steroid levels as well as psychiatric disorders were reported in women with 21-hydroxylase deficiency [13]. In our communitydwelling population of older adults, we have previously shown that variants of the CYP19A1 gene, which codes for aromatase, the key enzyme in the conversion of androgen to estrogen, were susceptibility factors for LLD in women specifically [29]. We also just reported that variants of the CYP11B1 gene coding for $11-\beta$ hydroxylase, the next enzymatic step after CYP21A2 in steroidogenesis pathway, were susceptibility factors for LLD in women [30]. Hence, several pathways related to steroidogenesis involving the major classes of steroids (progestogens, mineralocorticoids, glucocorticoids, androgens and estrogens), may shape to LLD in women. This may help explain sex-different vulnerability.

Our findings align with those of a recent meta-analysis of genome-wide association studies having linked these variants to depression. Indeed, $r s 389883$ was one of the 8 novel genome-wide significant index SNPs for broad depression phenotype which were replicated in a large population-based cohort [15]. Rs389883 was in high linkage disequilibrium with $r s 630379$ and with the non-synonymous coding SNP rs437179 [15]. These three SNPs were investigated for their association with diurnal cortisol secretion in older general population [14], but they failed to reach significant levels (p's 0.07-0.10). In neither study were potential sex-differences examined.

In congenital adrenal hyperplasia, mutations in the CYP21A2 gene can cause varying degrees of 21-hydroxylase activity loss leading to a range of phenotypes (from androgen excess for the milder form to virilization or "salt-wasting" with cortisol and mineralocorticoid deficiency for the most severe) [9]. However, the exact functional consequences of the variants in our study have not been examined.

\section{Conclusion}

Our findings provide new epidemiological support for CYP21A2 polymorphisms as independent susceptibility factors for LLD in a sex-specific manner. However, depression is a complex trait and it is likely that in 
addition to the effects of single genetic variants, depression is influenced by gene-environment and gene-gene interactions. Additional studies are needed to confirm these findings in other populations and to investigate the functionality of the associated variants.

\section{Limitations}

Limitations of our study include bias from excluding institutionalized participants and those with missing data. This may have decreased the overall power of the study. Despite the relatively large size of the sample, we could not examine specifically minor homozygotes due to their low frequencies. Our study focused on a specific candidate gene, rather than considering a number of genes involved in corticosteroid biosynthesis, or using a genome-wide association approach. Although candidategene studies are hypothesis driven rather than having the discovery approach of genome-wide studies, they remain of value to investigate known genes with strong a priori biological rationale. They are also more appropriate for relatively smaller studies and help to reduce the risk of false positives that was minimized by correcting for multiple comparisons.

\section{Abbreviations}

CES-D: Center for Epidemiologic Studies-Depression Scale; CYP21A2: Cytochrome P450, family 21, subfamily A, polypeptide 2; HPA: Hypothalamicpituitary-adrenal; LLD: Of late-life depression.

\section{Supplementary Information}

The online version contains supplementary material available at https://doi. org/10.1186/s13104-021-05616-6.

Additional file 1: Table S1. Number and frequency of CYP21A2 genotypes.

\section{Acknowledgements}

None.

\section{Authors' contributions}

MLA designed the study. MLA and KR lead the ESPRIT study and the collection of data. JN performed all statistical analyses. MLA, IC, and JR were involved in the interpretation of the data. MLA drafted the manuscript and all authors were involved in its revision and gave final approval to the submitted manuscript. All authors read and approved the final manuscript.

\section{Funding}

The ESPRIT project is financed by the regional government of LanguedocRoussillon, the Agence Nationale de la Recherche (ANR) Project 07 LVIE 004, and an unconditional grant from Novartis. Joanne Ryan is funded by a Dementia Research Leader fellowship [APP1135727] from the National Health and Medical Research Council (NHMRC), Australia. The funders had no role in the design and conduct of the study; in data collection, management, analysis, interpretation of the data; or writing the report preparation, review, or approval of the manuscript.

\section{Availability of data and materials}

The datasets analysed during the current study are available from the corresponding author on reasonable request.

\section{Declarations}

Ethics approval and consent to participate

All participants provided written informed consent before participating in the study. The study has been approved by the Ethical Committee of Sud Méditerranée III and University Hospital of Kremlin-Bicêtre, France.

\section{Consent for publication}

Not applicable.

\section{Competing interests}

The authors declare that they have no competing interests.

\section{Author details}

${ }^{1}$ INM, Univ Montpellier, INSERM, Montpellier, France. ${ }^{2}$ Centre for Clinical Brain Sciences, University of Edinburgh, Edinburgh, UK. ${ }^{3}$ Biological Neuropsychiatry and Dementia Unit, School of Public Health and Preventive Medicine, Monash University, Melbourne, VIC, Australia.

Received: 8 August 2020 Accepted: 15 May 2021

Published online: 25 May 2021

\section{References}

1. Belvederi Murri M, Pariante C, Mondelli V, Masotti M, Atti AR, Mellacqua Z, Antonioli M, Ghio L, Menchetti M, Zanetidou S, et al. HPA axis and aging in depression: systematic review and meta-analysis. Psychoneuroendocrinology. 2014;41:46-62.

2. Otte C, Hart S, Neylan TC, Marmar CR, Yaffe K, Mohr DC. A meta-analysis of cortisol response to challenge in human aging: importance of gender. Psychoneuroendocrinology. 2005;30(1):80-91.

3. Malki K, Keers R, Tosto MG, Lourdusamy A, Carboni L, Domenici E, Uher R, McGuffin P, Schalkwyk LC. The endogenous and reactive depression subtypes revisited: integrative animal and human studies implicate multiple distinct molecular mechanisms underlying major depressive disorder. BMC Med. 2014;12:73.

4. Peterson RE, Cai N, Dahl AW, Bigdeli TB, Edwards AC, Webb BT, Bacanu SA, Zaitlen N, Flint J, Kendler KS. Molecular genetic analysis subdivided by adversity exposure suggests etiologic heterogeneity in major depression. Am J Psychiatry. 2018;175(6):545-54.

5. Ancelin ML, Ryan J. 5-HTTLPR $\times$ stress hypothesis: is the debate over? Mol Psychiatry. 2018;23(11):2116-7.

6. Ancelin ML, Scali J, Norton J, Ritchie K, Dupuy AM, Chaudieu I, Ryan J. Heterogeneity in HPA axis dysregulation and serotonergic vulnerability to depression. Psychoneuroendocrinology. 2017;77:90-4

7. Ching-Lopez A, Cervilla J, Rivera M, Molina E, McKenney K, Ruiz-Perez I, Rodriguez-Barranco M, Gutierrez B. Epidemiological support for genetic variability at hypothalamic-pituitary-adrenal axis and serotonergic system as risk factors for major depression. Neuropsychiatr Dis Treat. 2015;11:2743-54

8. Concolino P, Mello E, Zuppi C, Capoluongo E. Molecular diagnosis of congenital adrenal hyperplasia due to 21-hydroxylase deficiency: an update of new CYP21A2 mutations. Clin Chem Lab Med. 2010;48(8):1057-62.

9. Pignatelli D, Carvalho BL, Palmeiro A, Barros A, Guerreiro SG, Macut D. The complexities in genotyping of congenital adrenal hyperplasia: 21-hydroxylase deficiency. Front Endocrinol (Lausanne). 2019;10:432.

10. Miller WL, Auchus RJ. The molecular biology, biochemistry, and physiology of human steroidogenesis and its disorders. Endocr Rev. 2011;32(1):81-151.

11. Charmandari E, Merke DP, Negro PJ, Keil MF, Martinez PE, Haim A, Gold PW, Chrousos GP. Endocrinologic and psychologic evaluation of 21-hydroxylase deficiency carriers and matched normal subjects: evidence for physical and/or psychologic vulnerability to stress. J Clin Endocrinol Metab. 2004:89(5):2228-36.

12. Falhammar $H$, Butwicka $A$, Landen $M$, Lichtenstein P, Nordenskjold $A$, Nordenstrom A, Frisen L. Increased psychiatric morbidity in men with congenital adrenal hyperplasia due to 21-hydroxylase deficiency. J Clin Endocrinol Metab. 2014;99(3):E554-560. 
13. Engberg $H$, Butwicka A, Nordenstrom A, Hirschberg AL, Falhammar $H$, Lichtenstein P, Nordenskjold A, Frisen L, Landen M. Congenital adrena hyperplasia and risk for psychiatric disorders in girls and women born between 1915 and 2010: a total population study. Psychoneuroendocrinology. 2015;60:195-205.

14. Velders FP, Kuningas M, Kumari M, Dekker MJ, Uitterlinden AG, Kirschbaum C, Hek K, Hofman A, Verhulst FC, Kivimaki M, et al. Genetics of cortisol secretion and depressive symptoms: a candidate gene and genome wide association approach. Psychoneuroendocrinology. 2011;36(7):1053-61.

15. Amare AT, Vaez A, Hsu YH, Direk N, Kamali Z, Howard DM, McIntosh AM, Tiemeier H, Bultmann U, Snieder H, et al. Bivariate genome-wide association analyses of the broad depression phenotype combined with major depressive disorder, bipolar disorder or schizophrenia reveal eight novel genetic loci for depression. Mol Psychiatry. 2020;25:1420-9.

16. Ancelin ML, Scali J, Ritchie K. Hormonal therapy and depression: are we overlooking an important therapeutic alternative? J Psychosom Res. 2007;62(4):473-85.

17. Chrousos GP. Stress and sex versus immunity and inflammation. Sci Signal. 2010;3(143):pe36.

18. Flint J, Kendler KS. The genetics of major depression. Neuron. 2014;81(3):484-503.

19. Kurina LM, Weiss LA, Graves SW, Parry R, Williams GH, Abney M, Ober C. Sex differences in the genetic basis of morning serum cortisol levels: genome-wide screen identifies two novel loci specific to women. J Clin Endocrinol Metab. 2005;90(8):4747-52.

20. Cohen-Woods S, Craig IW, McGuffin P. The current state of play on the molecular genetics of depression. Psychol Med. 2013;43(4):673-87.

21. Ritchie K, Artero S, Beluche I, Ancelin ML, Mann A, Dupuy AM, Malafosse A, Boulenger JP. Prevalence of DSM-IV psychiatric disorder in the French elderly population. Br J Psychiatry. 2004;184:147-52.

22. Ancelin ML, Carriere I, Scali J, Ritchie K, Chaudieu I, Ryan J. Angiotensinconverting enzyme gene variants are associated with both cortisol secretion and late-life depression. Transl Psychiatry. 2013;3:e322.
23. Sheehan DV, Lecrubier $Y$, Sheehan $\mathrm{KH}$, Amorim P, Janavs J, Weiller $E$, Hergueta T, Baker R, Dunbar GC. The Mini-International Neuropsychiatric Interview (M.I.N.I.): the development and validation of a structured diagnostic psychiatric interview for DSM-IV and ICD-10. J Clin Psychiatry. 1998;59(Suppl 20):22-33.

24. Radloff $L$. The CES-D scale: a self-report depression scale for research in the general population. Appl Psychol Measure. 1977;1:385-401.

25. Blazer DG. Depression in late life: review and commentary. J Gerontol A Biol Sci Med Sci. 2003;58(3):249-65.

26. Fiske A, Wetherell JL, Gatz M. Depression in older adults. Annu Rev Clin Psychol. 2009;5:363-89.

27. Folstein MF, Folstein SE, McHugh PR. "Mini-mental state". A practical method for grading the cognitive state of patients for the clinician. J Psychiatr Res. 1975;12(3):189-98.

28. Ancelin ML, Ripoche E, Dupuy AM, Barberger-Gateau P, Auriacombe S, Rouaud O, Berr C, Carriere I, Ritchie K. Sex differences in the associations between lipid levels and incident dementia. J Alzheimers Dis. 2013;34(2):519-28.

29. Ancelin ML, Norton J, Canonico M, Scarabin PY, Ritchie K, Ryan J. Aromatase (CYP19A1) gene variants, sex steroid levels, and late-life depression. Depress Anxiety. 2020;37(2):146-55.

30. Ancelin ML, Norton J, Ritchie K, Chaudieu I, Ryan J. 11ß-Hydroxylase (CYP11B1) gene variants and new-onset depression in later life. J Psychiatry Neurosci. 2021;46(1):E147-53.

\section{Publisher's Note}

Springer Nature remains neutral with regard to jurisdictional claims in published maps and institutional affiliations.
Ready to submit your research? Choose BMC and benefit from:

- fast, convenient online submission

- thorough peer review by experienced researchers in your field

- rapid publication on acceptance

- support for research data, including large and complex data types

- gold Open Access which fosters wider collaboration and increased citations

- maximum visibility for your research: over $100 \mathrm{M}$ website views per year

At BMC, research is always in progress.

Learn more biomedcentral.com/submissions 